\title{
ADDRESS
}

\section{Ryukichi Itoh}

President of The Iron and Steel Institute of Japan

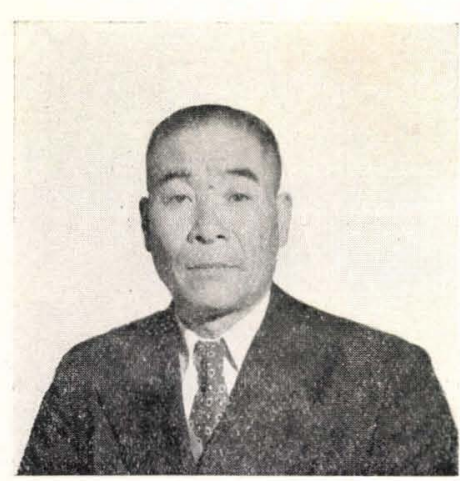

Nippon Tekko Kyokai (The Tron and Steel Institute of Japan) was established in February 1915 for the purpose of studying and surveying scientific, technical and all other problems concerning iron and steel, and thus contributing to the improvement and development of the iron and steel industries in Japan. Since then, constant efforts have been made toward this end.

The results of this research are made public through regular semi-annual lecture meetings and various special meetings. The Institute also has established the Hattori Prize, Komura Prize, Tawara Prize, Watanabe Prize and other prizes to commend every year those who have made specially valuable contributions to scientific and technical developments in iron and steel technology. These prizes are acknowledged as authoritative in this field.

When the Institute was first established, it had about 900 members. Now it has grown to a membership of approximately 5,000. The periodical Tetsu-toHagané was first issued on March 30, 1915 as the technical Journal of the Institute. This is believed to be the oldest scientific and technical magazine on iron and steel industry in Japan - reaching its 38 th anniversary this year. Over this period, the magazine has kept pace with the development of the iron and steel industry and has made significant contributions in both theory and practice. Many authoritative experts have been associated with the Institute as members and as contributors to this Journal.

So far, this magazine has been distributed only among Japanese readers. Recently, however, it has been suggested that it would be useful to send the Journal abroad to get comments and suggestions from those in foreign countries. This is why an English edition of "Tetsu-to-Hagané" is sent to our overseas friends today.

The iron and steel industry of the world has made amazing progress, but, as the mother of human culture, there remains room for still further development. It is our sincere hope that this Institute and this Journal through continuous study and research, will play a part in the advance of the iron and steel industry throughout the world. We sincerely request your cooperation and assistance in making "Tetsu-to-Hagané" a better means to this goal. 